\section{Superior accuracy}

Most dentists will agree that articulation paper isn't always reliable as a dental diagnostic tool. That's why Clark Dental offers the T-scan digital occlusal analyser, which can be used to measure and assess the stability of a patient's bite.

Clinically recognised and research validated, the T-scan's innovative sensor technology provides timely and detailed occlusal data that can be used to help treat patients with superior accuracy.

Using the T-scan's intuitive software, clinicians are better able to communicate about proposed treatment, facilitating greater patient compliance. This ensures costly remakes are prevented, enabling practitioners to maximise on valuable chair time and achieve high patient satisfaction.

For more information, call Clark Dental on 01270 613750, email info@ clarkdentalsales.co.uk, or visit www. tekscan.com.

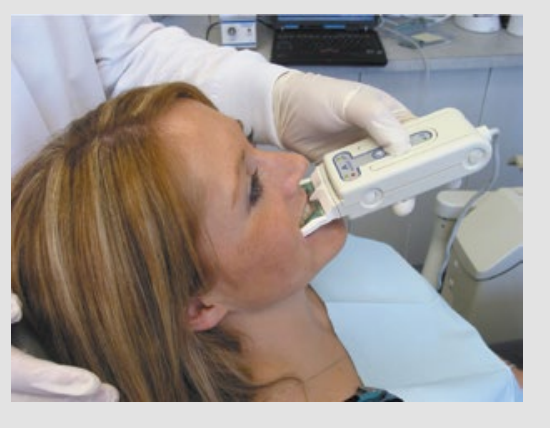

\section{A new approach to air compressor excellence}

Your air compressor supports your most basic actions as a dental professional. So, why not ensure that your air compressor remains always in perfect working order by enlisting the help of DentalAir?

No more wasting time on maintaining the system yourself, with DentalAir's unique Total Air Care service you will receive a brand new oil-free air compressor that will be fitted as soon as you sign up. This system will be regularly maintained, serviced and have air qualities tested to ensure that you are keeping compliant and putting patient safety first.

Take away the stress and keep things simple with DentalAir.

For more information, contact DentalAir at info@dentalair.com or call 08009757530.

\title{
Topical treatments that strengthen and protect
}

The consequences of the COVID-19 pandemic have and will continue to pose significant challenges for the dental profession. While practices have been closed, elderly and high-risk patients especially have suffered from a lack of access to dental care, putting them at increased risk of coronal caries, root surface caries and hypersensitivity.

Once exposed to the oral environment, root surfaces are at greater risk of demineralisation, especially when patients have reduced saliva flow and diminished buffering capabilities. By elevating the levels of calcium in saliva and dental plaque, topical treatments can reduce the harmful effects of plaque-derived acids and enhance remineralisation.

GC's Tooth Mousse and MI Paste Plus topical applications provide immediate relief for patients suffering from tooth sensitivity while providing a natural defence against caries. They can be applied either professionally in-practice or selfadministered by patients at home and are an excellent option for non-chairside management of high-risk patients.

Tooth Mousse and MI Paste Plus with bio-available calcium and phosphate provide greater resistance to acid attacks by inhibiting enamel demineralisation and inducing remineralisation, both on the surface and sub-surface of the tooth. They reduce hypersensitivity by obturating open dentinal tubules and prevent initial caries forming due to their anti-cariogenic properties.

Tooth Mousse bio-available calcium and phosphate - without fluoride

MI Paste Plus bio-available calcium and phosphate - with fluoride.

- Non-chairside management of high-risk patients

- Topical application

- Rapid relief from sensitivity

- Patient can self-administer

- Five different flavours

- Caries prevention

- Reverses white spot lesions

- Retail solution - can be sold in practice

- Additional income streams for DCPs.

For further information, get in touch with GC UK today to request a virtual meeting with one of the team to discuss GC's nonchairside topical treatments. Contact GC UK Ltd on 01908 218999, email info.uk@ gc.dental or visit www.gceurope.com.

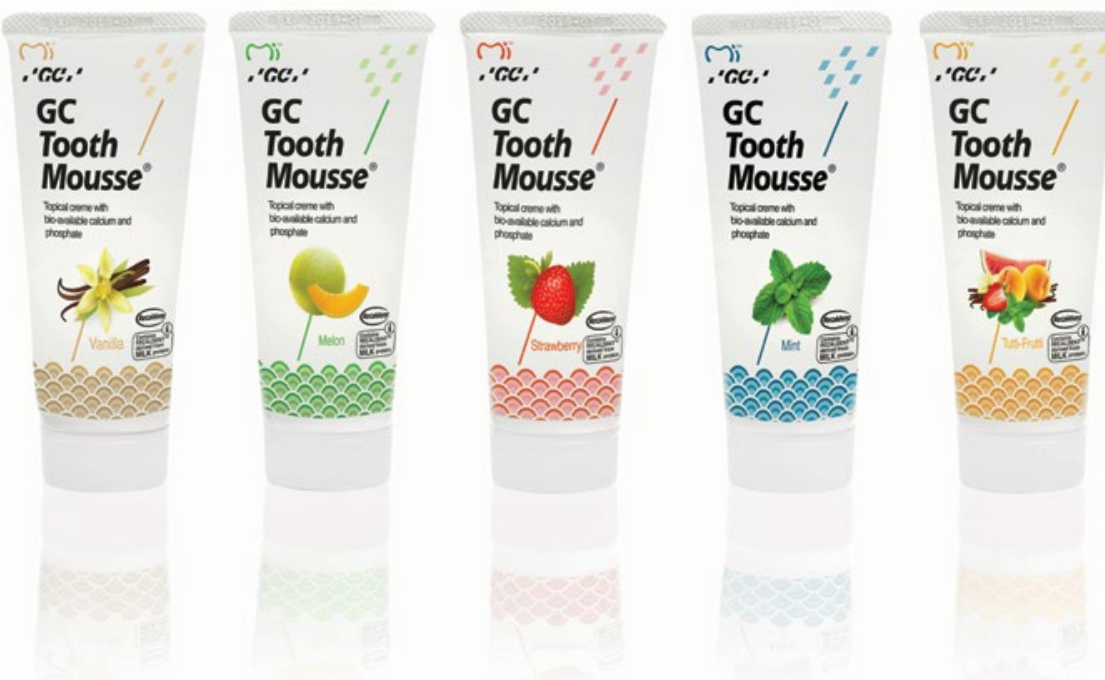

\section{Keep in touch, keep your patients smiling}

Although you may not be seeing patients face to face, it is more important than ever that they are motivated to commit to your daily oral hygiene advice. Sensodyne has also supported a Q\&A webinar by the College of General
Dentistry and FGDP(UK) based on their published guidance 'Implications of COVID-19 for the safe management of general dental practice. The webinar and guidance can also be accessed via www. gskworkingtogether.co.uk. 